\title{
Exploring the relationship between technical and service characteristics
}

\author{
Paul Windrum • Cecilia Diaz • Despoina Filiou
}

Published online: 6 May 2009

(C) Springer-Verlag 2009

\begin{abstract}
The paper explores the complex relationship between technical and service characteristics discussed by the Saviotti-Metcalfe model of innovation. It is proposed that principal components analysis (PCA) is a more appropriate method of analysing this relationship than approaches previously used. A PCA is performed on a dataset of mobile phone handsets for the period 2003 to 2008. In addition to the relationship between technical and service characteristics, the analysis explores the existence of clusters of ergonomic characteristics within mobile phone handsets. The findings indicate that a limited set of core technology components underpin the large set of service characteristics offered by mobile phone handsets, and that the mapping between technical and service characteristics can be highly complex.
\end{abstract}

Special Issue on 'Product Characteristics and Innovation', Journal of Evolutionary Economics, P.P. Saviotti and K. Frenken (eds.).

P. Windrum $(\varangle) \cdot$ D. Filiou

Centre for International Business and Innovation (CIBI), Manchester Metropolitan

University Business School, Aytoun Building, Aytoun Street,

Manchester M1 3GH, UK

e-mail: p.windrum@mmu.ac.uk

D. Filiou

e-mail: d.filiou@mmu.ac.uk

P. Windrum

Max Planck Institute for Economics, Jena, Germany

C. Diaz

Manchester Metropolitan University Business School, Aytoun Building,

Aytoun Street, Manchester M1 3GH, UK

e-mail: c.diaz@mmu.ac.uk 
Keywords Product characteristics • Saviotti-Metcalfe model • Principal component analysis $\cdot$ Mobile phone

JEL Classification D12 • O33

\section{Introduction}

The Saviotti and Metcalfe (1984) model of product innovation is wellestablished within modern innovation theory. The authors' stated aim was to advance empirical research through the development of a framework that brings together output indicators of innovation and stimulates the development of new, improved indicators. The framework is underpinned by Lancaster's work on characteristics (Lancaster 1966, 1971). Differences in the prices charged for rival products reflect differences in the quality of the 'services characteristics' that are offered to consumers. Further, the quality of service characteristics depends on an underpinning set of technologies that are embodied in a product. Hence, variation in price and the quality of 'service characteristics' can be directly tied to the 'technical characteristics' of a set of competing technologies. Saviotti and Metcalfe highlight complex relationships between clusters of technical and service characteristics, and the fluidity of these relationships over time.

This paper addresses an important limitation within the existing empirical work on characteristics; namely, the relationship between technical and service characteristics that lies at the heart of the Saviotti-Metcalfe model. This has not been critically examined within the existing body of empirical research. In their 1984 paper, Saviotti and Metcalfe propose the application of the hedonic price method to empirically explore the relationship between price and technical characteristics (or, alternatively, between price and service characteristics). ${ }^{1}$ A number of papers using this method followed. Saviotti applied the hedonic method to a study of automobiles (Saviotti 1985) and helicopters (Saviotti and Tricket 1993); Trajtenberg (1989) applied it to data on computed axial tomography (CAT) scanners; and Grupp (1998) to data on bio-diagnostic kits and capital goods. Estimating the shadow prices of technical characteristics does not provide insight into the relationship between service characteristics and technical characteristics. The same limitation applies to work by Frenken and colleagues (Frenken et al. 1999; Frenken and Leydesdorff 2000) who apply entropy and Weitzman techniques to examine variety within service characteristics space or, alternatively, within technical characteristics space. They did

\footnotetext{
${ }^{1}$ The hedonic approach to the measurement of technological change has its origins in the work of Court (1939), Stone (1956), Lancaster (1966), and Griliches (1957, 1971).
} 
not analyse the correspondence between variety in service characteristics and variety in technical characteristics. ${ }^{2}$

In order to open up a discussion of the complex relationship between technical and service characteristics, we apply the method of principal components analysis (PCA). PCA is attractive because it is a well-established statistical procedure for examining complex, relationships, and is simple to implement (Dunteman 1994; Stevens 1992). In this paper we apply PCA to a dataset of technical and service characteristics of mobile phone handsets, collected for the period 2003 to 2008. There are two striking aspects of this technology. First, there is the portability of the design. Consumers require a handset that is relatively compact and lightweight but which can offer a variety of services. There is therefore both an ergonomic component in the aesthetic look and feel of this manufactured artefact, and a technological component with ever more sophisticated features and service characteristics offered within the same basic design configuration. This is very much within Lancaster's original discussion of consumer demand for service characteristics, which formed the starting point of the Saviotti and Metcalfe model.

The remainder of the paper is organised as follows. "Section 2" reviews the Saviotti-Metcalfe model of innovation. This highlights their discussion of the importance of overlapping clusters of technical characteristics that support a set of distinct service characteristics. It is argued that a set of core technologies underpin a larger number of service characteristics. What is more, there can be multiple, complex links between technical and service characteristics. This argument is derived from Dosi's work on technological paradigms, which Saviotti and Metcalfe used to operationalise their model.

"Section 3" provides a detailed discussion of the technical and the service characteristics of the modern mobile phone. There are three core technologies that underpin this design: battery, screen, and microchip technologies. We take three service characteristics that are popular on modern phones: cameras, for taking and transmitting still images; video facilities for recording, downloading and watching (short) video clips; and music facilities for playing and storing songs. A set of research hypotheses are derived. Three of these hypotheses consider correlations between an individual service characteristic (i.e. photographs, video, and music services, respectively) and the set of underpinning battery, screen, and microchip technical characteristics. The fourth hypotheses considers the existence of correlations between the physical/ergonomic features of mobile phone handsets.

"Section 4" discuses the method of principal components analysis and describes the characteristics dataset that is used to test the research hypothesis.

\footnotetext{
${ }^{2}$ The Weitzman variety measure is only applied to technical characteristics, which are assumed to be discrete and orthogonal to one another in Hamming distance. A separate analysis, using the entropy measure on Euclidean space, is applied to service characteristics. These service characteristics are once again assumed to be discrete and orthogonal to one another.
} 
"Section 5" reports results of the PCA on mobile phone service and technical characteristics. As we shall see, these strongly support the Saviotti-Metcalfe model of the relationship between technical and service characteristics. "Section 6" concludes by pulling together the findings of the paper and considers future research opportunities.

\section{Empirical applications of the Saviotti-Metcalfe model}

The Saviotti-Metcalfe model (1984) was seminal in establishing a 'characteristics approach' to modelling innovation. It developed Lancaster's work on demand (Lancaster 1966, 1971). Lancaster observed that all types of products (both manufactured goods and immaterial services) can be described by the bundle of 'intrinsic characteristics' (or attributes) that they embody. These characteristics are the stream of services, provided by a good/service, which the purchaser consumes over the lifetime of the purchased product. Lancaster observed that consumers choose between alternative bundles of service characteristics and prices that are offered on the market by producers. Lancaster used the example of the electric kettle to illustrate his point. Different designs offer different quality and price points in terms of the volume of water that can be boiled and the time taken. Their designs also offer alternative aesthetic and ergonomic (touch and feel) characteristics that are valued by consumers.

Saviotti and Metcalfe (1984) took Lancaster's insight and translated it into a model of innovation (also see Saviotti 1985, 1996). 'Service characteristics' are equivalent to what Lancaster called the intrinsic characteristics from which consumers derive utility through consumption. Saviotti and Metcalfe link these service characteristics to a set of underpinning technical characteristics. Each product has a set of core technologies whose performance can be described by a vector of 'technical characteristics'. Improvements in technical characteristics, achieved through $\mathrm{R} \& \mathrm{D}$, enhance the quality of the associated service characteristics that are of interest to consumers.

The relationship between service and technical characteristics is presented in Fig. 1. ${ }^{3}$ For example, an automobile's service characteristics of speed and fuel efficiency clearly depend on the physical, technical characteristics of its engine. Given the underpinning technologies, one will expect to see cumulativeness in innovation and specific trajectories within which service characteristics can be improved.

'Process characteristics' are governed by capital equipment and by their underpinning process technologies (Saviotti and Metcalfe 1984, p. 144). Saviotti $(1985,1996)$ subsequently expanded this to include tangible assets (such as plant and equipment), intangible assets (such as brand name, copyright, and

\footnotetext{
${ }^{3}$ These are clearly defined for manufactured goods, though possibly less so for services (see Gallouj and Weinstein1997; and Windrum and García-Goñi 2008.
} 
Fig. 1 Relationship between process, technical, and service characteristics in the Saviotti-Metcalfe model

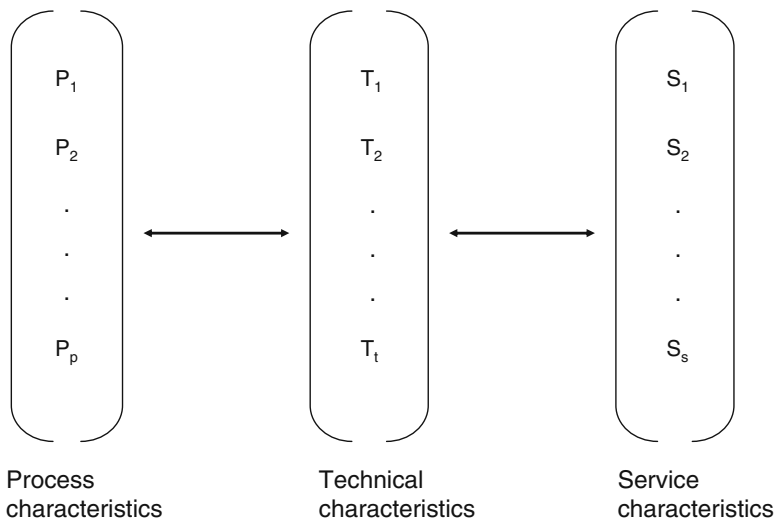

patents), human resources (such as education, training, experience, and skills of individual staff), and organisational resources (such as corporate culture, organisational structure, rules, and the procedures of the firm) that range from the design to production to marketing.

As noted in "Section 1," a key aspect of the Saviotti-Metcalfe model is the relationship between technical and service characteristics. In the simplest case, a service characteristic may depend on a single technical component. However, Saviotti and Metcalfe highlight the possible existence of complex relationships between clusters of technical and service characteristics, and the fluidity of relationships over time. An innovation in one technical component may affect a number of co-related technical components and a number of service characteristics.

Saviotti (1996) makes clear that Dosi's theory of technological paradigms and trajectories (Dosi 1982) is essential to operationalising the model; structuring the discussion of the relationship between technical and service characteristics, and a discussion of how technological change alters technical and service characteristics over time. Drawing on T.S. Kuhn's work on scientific paradigms and the development of science (Kuhn 1962), Dosi defines a technological paradigm as a “'model' and a 'pattern' of solution of selected technological problems based on selected principles derived from natural science and selected material technologies" (Dosi 1982, p. 152).

Dosi states that one should think of a product as a cluster of technologies rather than a single, independent technology. For Dosi, a technology is "a set of pieces of knowledge both directly 'practical' (related to concrete problems and devices) and theoretical (but practically applicable although not necessarily already applied), know-how, methods, procedures, experience of success and failure and also, of course, physical devices and equipment" (Dosi 1982, p. 151). A 'technological trajectory' is the pattern of 'normal' problem solving activity (the parallel of 'normal science') that seeks incremental performance improvements based on the existing set of accepted technical frames and solutions. By contrast, a radical innovation is founded on the creation of a 
new set of technology frames and solutions, and results in a new trajectory that is qualitatively different to the old technology trajectory. This may initially be sparked by the incremental development of a technology. As engineers seek to improve the performance of a product, they realise the need to engage in a radical redesign of the core technologies and/or the sets of core technologies that are used in the product. This can lead to a new set of conceptual models and solutions, thereby establishing a new paradigm with a new technological trajectory.

Implementing these ideas into their model of technical and service characteristics, Saviotti and Metcalfe proposed that complex relationships can exist between the clusters of technologies that underpin different products. What is more, the relationship between technical and service characteristics can change over time (Saviotti and Metcalfe 1984, pp. 142-143). Multiple connections may exist between the technical characteristics and the set of final service characteristics within a single product, as illustrated in Fig. 2.

The purpose of this paper is to empirically explore the existence of clusters of service and technical characteristics, such as those indicated in Fig. 2. This has not been directly examined in previous empirical studies. The core research proposition which we wish to empirically explore in this paper is the following:

Proposition 1 Service characteristics are produced by overlapping clusters of technical characteristics.

In addition to clusters of technical and service characteristics, a product may contain service characteristics that are determined by non-technological

Fig. 2 Mapping between technical and service characteristics

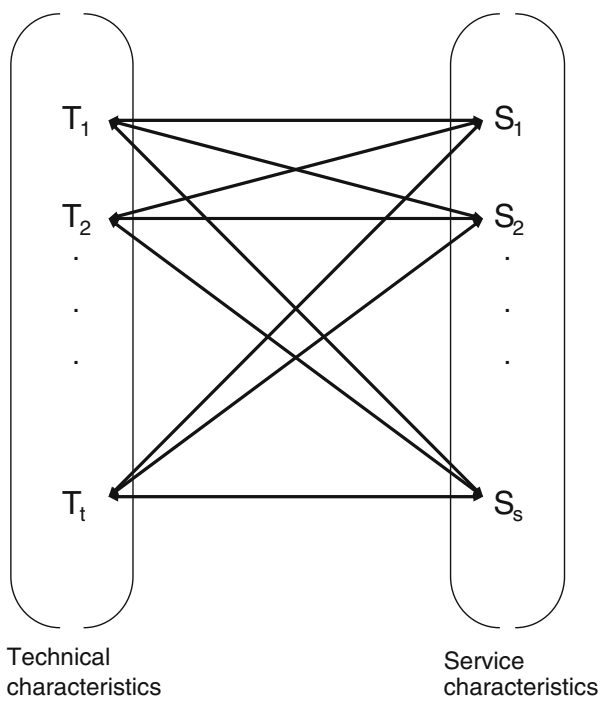


clusters. There may be, as Lancaster proposed, non-technical, ergonomic features of a product that provide service characteristics which are attractive to the consumer. This provides our second research proposition:

\section{Proposition 2 A product can contain one or more non-technological clusters.}

In order to conduct the analysis, we will apply principal components analysis (PCA) to a dataset of mobile phone characteristics. PCA is a method that is used to analyse patterns of correlations among a set of original variables. While PCA is commonly used as a technique for reducing data for regression analysis, it can also be used to identify patterns of behaviours or actions which are shared by a particular group of variables - here clusters of service and technical characteristics, or to differentiate one cluster of characteristics from another. In this paper we conduct a principal components analysis on a dataset of mobile phone characteristics that has been collected for the period September 2003 to January 2008. Prior to conducting this analysis, we first need to consider the core technologies that underpin the key features and service characteristics of a modern mobile phone. This is the focus of the next section.

\section{Technical and service characteristics of mobile phones}

The construction of indices of key service characteristics and core technical characteristics is non-trivial. It requires an availability of good quality data, and knowledge of the technology and the industry on the part of the researcher (Saviotti and Metcalfe 1984; Saviotti 1985; Grupp 1998). The collection and assessment of characteristics data can be time intensive, even for a single product or technology. Additionally, and in contrast to patent statistics for instance, there is not a standard classification of characteristics (Gambardella 2001). This opens up issues of omission and consistency. For example, Saviotti (1985) describes how researchers in three studies used different characteristics to describe agricultural tractors sold in the UK market, rendering void any attempt to compare their research findings.

Given the lack of agreed standards, the researcher needs to be clear about decisions taken in the selection of data sources (i.e. the strengths and weaknesses of the sources used, the completeness and consistency of those sources), and decisions taken in the construction of the dataset. Take, as an example of the latter, the battery life of a mobile phone. Should this be treated as a technical characteristic or a service characteristic? It could be argued that battery life is a service characteristic. We treat battery technology as a technical characteristic because it is core to portable technologies such as mobile phones. Different battery technologies are available, each with their strengths and weaknesses in terms of average life times, cost, and weight. Given estimates of the energy demands of the different services offered by a particular phone design, and knowing the technical characteristics of the alternative battery technologies that are available, designers choose an appropriate battery 
option. Determining the maximum portability (in hours) of the phone design in this way ensures that users do not need to recharge on a daily basis. Certainly, if users faced such an inconvenience, then one might well expect battery type to enter into their purchasing considerations. As such, it would need to be treated as a service characteristic in its own right. This may occur in the future if, for instance, real time video and music services grow in popularity and improvements in battery technology are unable to keep up with the rate of increase in energy requirements. This example highlights the contingency of decisions made by researchers in defining technical and service characteristics, and the contestability of decisions. Good practice requires that researchers are explicit about the basis or their decisions.

\subsection{Technical characteristics}

One can identify three core technologies that determine the 'technical characteristics' of the modern mobile phone. In addition to battery technology, there is screen technology and microchip technology.

\subsubsection{Battery technology}

As noted, the underpinning battery technology determines the maximum portability (in hours) of a mobile phone. Three alternative types of batteries are currently available for use in mobile phones: nickel-metal-hydride (Nimh); lithium-ion (Li-ion); and lithium-ion-polymer (Li-Po). Of these, Li-ion is currently predominant in mobile phones. First launched in early 1991, Li-ion technology offers higher electrochemical potential and has the largest density for weight of all currently available options (van Schalwijk and Scrosati 2002). What is more, the Li-ion battery is a low maintenance design, i.e. there is no memory discharge and has a low self-discharge rate, and does not require prolonged priming when new.

Current Li-ion technology does have its drawbacks, however. A major issue is the relatively high cost of production compared to the other battery types. There were well documented problems of early versions exploding. This was due to the instability of lithium metal. Temperatures, particularly during charging, can quickly rise to the melting point of metallic lithium, resulting in a violent reaction. The problem was solved by substituting non-metallic elements, and today Li-ion is possibly the safest battery on the market. A potential disadvantage that remains is that of battery ageing. However, this is less of an issue for consumers who regularly change their phone. Network companies offer their contract customers the possibility to upgrade their phones every year, and, hence, the batteries contained therein.

Nickel-metal-hydride (Nimh) was launched at the end of the 1980s. It quickly replaced the nickel-cadmium batteries used in the earliest mobile phones. Nimh offered 30-40\% higher capacity than nickel-cadmium, was less prone to battery memory loss, offered simple storage and transportation, and was more environmentally friendly compared than nickel-cadmium, which is a 
highly toxic metal (Linden and Reddy 2001). Nimh batteries have largely been replaced by Li-ion batteries. Nimh batteries have a number of weaknesses compared with Li-ion batteries. Nihm has a relatively limited service life: performance starts to deteriorate after 200-300 charge/discharge cycles. Nimh also has a relatively short storage life of 3 years. As noted previously, this may not necessarily be a major disadvantage, given the frequent replacement of phones, and their batteries, by customers. A definite limitation is the limited discharge current of Nimh batteries. While they are capable of delivering high discharge currents, heavy load reduces the battery's cycle life. Finally, the technology suffers from high self-discharge.

The third and final type of battery that can be found in modern mobile phones is the Li-lithium-ion-polymer (Po) battery. Sony-Ericsson is currently the main advocate of the Po battery. What differentiates Po from other battery technologies is the electrolyte that is used. Unfortunately, the dry lithium polymer suffers from poor conductivity. To ameliorate this problem, a gelled electrolyte is added. Po batteries have a number of advantages over current $\mathrm{Li}$-ion technology. First, one can produce very low profile batteries; batteries with the profile of a credit card are feasible. Second, there is a flexibility of battery form. Po batteries can be produced in almost any form, freeing battery manufacturers and phone designers from standard cell formats. Third, the technology can be produced in high volumes, so any reasonably sized battery can be produced economically. Fourth, Po batteries are very lightweight. Gelled electrolytes enable simplified packaging by eliminating the need for a metal shell. Fifth, Po batteries offer improved safety. They are more resistant to overcharge than $\mathrm{Li}$-ion batteries, with less chance of electrolyte leakages.

Compared to Li-ion technology, Po technology has three main weaknesses. The first is a lower energy density and decreased cycle count compared to Liion. Second, due to lower production levels, they are currently more expensive to manufacture. Third, they have a higher cost-to-energy ratio than Li-ion.

\subsubsection{Microchip technology}

Microchip technology determines the maximum memory (in bytes) of a mobile phone and, hence, the quality of features such photos, video, and music storage. Two alternative forms of memory technology underpin the current generation of mobile phones: internal memory and removable memory. Until recently, internal memory exploited two microchips; one dedicated to operating system software and application software; the other dedicated to pictures, video, and music storage. Recently, there has been experimentation with a single chip set to perform all functions. The key attraction here is the saving of space within the mobile phone.

'Flash memory' is used for both internal and removable memory in mobile phones. Flash memory is non-volatile computer memory that can be electrically erased and reprogrammed. The key advantage of non-volatile memory is that it does not require energy in order to store information on a chipset. 
Besides mobile phones, non-volatile memory is used in PDAs and digital cameras. By contrast, PCs use volatile DRAM memory.

There are two alternative types of flash memory used in the current generation of mobile phones: NOR and NAND. ${ }^{4}$ NOR flash was first introduced by Intel in 1988 as an alternative to EPROM and EEPROM based devices. In 1989 Toshiba introduced NAND flash architecture. This addressed the need for lower cost per bit, higher performance, and disk-like memory. Technically, NOR and NAND flash differ in two important ways: the connections of the individual memory cells are different, and the interface provided for reading and writing the memory is different (NOR allows random-access for reading, NAND only allows page access). The NOR configuration consists of individual memory cells that are connected in parallel. This facilitates random access and provides a fast response time. NOR is typically used for fast response rate/low density applications, such as code storage. Within mobile phones, it is most effective for application storage.

NAND is a serial memory cell that has 1 less contact per pair of cells than NOR memory, making NAND less expensive to produce. NAND is popular because it is a cost-effective means of producing high density storage devices with fast response rates. Indeed, NAND was specifically developed as a high density storage alternative to NOR (the endurance of a typical NAND flash is 1,000,000 cycles compared with a typical NOR flash of 100,000 cycles). In mobile phones, NAND is typically used for high density storage and high speed programme/erase applications such as music, video, picture data storage.

\subsubsection{Screen technology}

Screen technology is the third core technology underpinning the modern mobile phone. The quality of a screen is governed by the number of pixels per square centimetre. This is directly related to the quality of the Liquid Crystal Display (LCD) of the phone. The type of LCD screen determines the resolution. This is particularly important for the quality (service characteristics) of its camera and video facilities. An LCD is a thin, flat display device, made up of a certain number of colours or monochrome pixel arrays, taking the form of a light source or reflector. An LCD is usually utilised in battery powered electronic devices because it requires very small amounts of electric power. ${ }^{5}$

LCD displays are divided into two groups: passive-matrix and active-matrix (Polymers and Liquid Crystals 2008). Passive matrix types include super twisted nematic (STN) and the colour version STN (CSTN). In a passive

\footnotetext{
${ }^{4}$ NOR stands for Not 'OR'. A NOR gate is a basic logic gate similar to an OR gate, but with the output inverted. NAND stands for Not 'AND'. A NAND gate is a basic logic gate similar to an AND gate but with an inverted output.

${ }^{5}$ For an informed and clearly written introduction to LCDs, the reader is referred to the website of the Liquid Crystal Technology Group (http://plc.cwru.edu/tutorial).
} 
matrix, each row or column of the display has a single electrical circuit. The pixels are addressed one at a time, by row and column address. It is called 'passive' because a pixel must retain its state between refreshes, without the benefit of a steady electrical charge. Due to the low total pixel number and low response times, screen resolution of passive matrix types is poor. As the number of pixels increase, this type of display becomes increasingly less feasible. Hence, it is mainly found in older mobile phones and in low-end mobile phones. Active matrix, thin-film transistor (TFT), LCDs contain a greater number of pixels and offer far better colour resolution. Each pixel has its own dedicated transistor, allowing each column line to access one pixel. Almost all new mobile phone models have TFT displays.

\subsection{Service characteristics}

In order to research Proposition 1, we consider the relationship between the core technologies just discussed and three key service characteristics that are popular on modern phones: cameras for taking and transmitting still images, video facilities for recording, downloading and watching (short) video clips, and music facilities for playing and storing songs. In order to research the second of our research proposals, we also consider the factors determining the ergonomic comfort of a mobile phone. Let us take each of these in turn.

\subsubsection{Camera quality}

The quality of a still image that is viewed on a mobile phone is directly governed by the pixel resolution of the phone's camera software. One would expect a correlation to exist between the quality of this service characteristic and the quality of the core technologies, i.e. the technical characteristics, which underpin the mobile phone. Perhaps the most obvious is the resolution of the LCD screen. Memory is another important factor, as better quality images with higher pixel content require more memory. Finally, larger and better LCD displays require more power, placing greater demands on battery efficiency. This provides us with the first of our test hypotheses.

Hypothesis 1: There is a positive correlation between the pixel resolution of camera software, LCD pixel resolution, phone memory, and battery life.

\subsubsection{Video quality}

Perhaps not surprisingly, the factors governing video quality are not too dissimilar to those governing the quality of a still image-given that video is essentially a stream of still images combined with a sound recording. The key determinant of video quality is the software that governs the pixel resolution of the image and the sound resolution. As with still images, one expects a positive correlation to exist between the quality of this service characteristic 
and the technical characteristics of the core battery, memory and screen technologies.

Hypothesis 2: There is a positive correlation between the pixel resolution of video software, LCD pixel resolution, phone memory, and battery life.

\subsubsection{Music quality}

The quality of digital music playback depends on the sampling bit rate of the recording. Further, it is heavily dependent on the memory and the battery life of the phone. The higher the sampling rate of a recording, the better its quality. A number of different formats are currently available. These include ATRAC, AAC, MP3, and MP4. In terms of sound quality what matters is the sampling rate, not the particular format that is used. The major downside with higher sampling rates is that they require more memory per track. As with video, playing continuous music is very demanding in terms of energy, and so the battery life of a phone becomes an important technological factor.

Hypothesis 3: There is a positive correlation between sampling rates of the music software, phone memory, and battery life.

\subsection{Non-technological service characteristics}

Finally, we will examine the existence of a correlation between the ergonomic comfort of using a mobile phone and its size (volume) and weight. One consequence of the focus on technical characteristics in past empirical research has been an ignoring of design ergonomics. Yet, as discussed in "Section 1" and "Section 2," the ergonomic characteristics of product designs play a prominent role in Lancaster's theoretical work (Lancaster 1966, 1971).

Ergonomic characteristics provide a set of non-technologically determined service characteristics. The 'ideal' size and weight of a mobile phone is determined by the human anatomy, with which the device interacts. In this case, the ideal size is governed by the size of human fingers that operate the phone and the palm of the hand in which a phone rests, while ideal weight is governed by the strength of the human wrist and arm that must hold and carry the device.

There may well be an ideal range of size and range of weight that consumers demand. A very large and heavy phone is cumbersome to carry and cannot be stored easily. At the other end of the scale, a phone that is very small cannot by operated effectively by human fingers, increasing the probability of typing errors.

There is a further ergonomic characteristic to consider: the resolution power of the human eye determines a minimum effective size for an LCD screen. Increasing screen size and resolution has a direct impact on the overall size of a mobile phone. The trend towards camera phones offering picture taking, picture sharing, and retrieval of online data from websites requires higher screen image quality. Image quality has thus become an important service 
characteristic in its own right. The larger the screen, the greater the number of screen pixels, and the better the quality of image resolution that can be displayed. Given the increased demand for picture and video services, and the fact that larger screens are easier to view than smaller screens, one might reasonably expect phone sizes and weights to be at the upper limit of the ergonomically comfortable range. Recent examples of this trend include the Nokia $\mathrm{N}$ series and the Blackberry models. These larger sized handsets offer more internet and camera features than smaller sized phones.

There is, however, a downside to larger screens. To maintain a given level of image resolution, larger screens require a larger number of pixels. This necessitates a commensurate increase in the overall dimensions of the phone (its volume) and an increase in weight. The negative correlation between battery life (hours), on the one hand; and screen size, volume, and weight, on the other, reflects the current limits of battery technology discussed above. The larger the size of screen, the greater the power required to produce a given level of brightness, and, hence, the greater the drain on battery life.

Taken together, one would expect a positive correlation between screen size, phone volume, and phone weight. A limiting factor is the battery power needed to operate a larger screen. One would expect a negative correlation between battery life and the other ergonomic characteristics of screen size, phone volume, and phone weight.

Hypothesis 4: There is a positive correlation between screen size and the volume and weight of a mobile phone, and a negative correlation between battery life and screen size, phone volume, and phone weight.

If this set of expected correlations exists, it will be identifiable as a separate and distinct principal component within the estimated models that are developed to test Hypotheses 1,2 and 3. One of the advantages of the PCA method is that one can conduct joint hypothesis testing such as this (Ahamad 1967). For example, when testing technical and service characteristics governing camera quality (Hypothesis 1), we can additionally test the relationship between battery life and the ergonomic variables of overall handset size (volume), screen size, weight. If a distinct set of ergonomic correlations do exist, then this will show up as a separate estimated principal component containing these four variables. Further, we have argued that the expected sign for battery life within this estimated component is negative.

To summarise, we have identified a set of four testable hypotheses. Three of these investigate the relationship between specific service characteristics and the technical characteristics of the core technologies that underpin mobile phones. The service characteristics that we test are camera quality, video quality, and music quality. The fourth hypothesis investigates the existence of a distinct set of ergonomic characteristics, determined by the physical proportions of a mobile phone and how these proportions relate to the human body. 


\section{Principal component analysis and mobile phone dataset}

Principal components analysis (PCA) is a method that is used to analyse patterns of correlations among a set of original variables. It generates a number of 'principal components' that capture interrelationships between the original variables and their tendency for these variables to co-appear (Dunteman 1994).

PCA tends to be used as data reduction technique, i.e. for grouping a number of independent variables for regression purposes. However, PCA can be used as an exploratory statistical technique to analyse correlations between groups of distinct variables as they appear in the principal components. This use of PCA is more common amongst non-economists, and there is a well documented literature stretching back to Ahamad (1967, 1968). There are some previous examples of this use of PCA in the innovation literature, where researchers have explored patterns of interrelationships among variables to shed light on associations and links for which little knowledge exists (Tether and Tajar 2008). For example, Coombs and Tomlinson (1998) used PCA to explore whether distinct styles of innovative behaviour can be identified between service and manufacturing firms. Filiou and Windrum (2007) used PCA to examine the behaviour of biotech and pharma firms in cooperation agreements and their underlying tendencies to systematically interrelate exploration and exploitation via these cooperation agreements. The benefit of PCA, compared to other exploratory statistical techniques, such as factor analysis, is that it does not make prior assumptions regarding the extent and the structure of interdependencies among the original variables (Stevens 1992). In terms of the current paper, the attraction of PCA is that it provides us with a relatively simple and effective tool with which to undertake an exploratory analysis of the relationship between service characteristics and technical characteristics within a mobile phone dataset.

In order to apply PCA, we must assess the number of composite variables required to achieve a sound representation of the original set of variables. This is assessed using a combination of statistical criteria. These include the Kaiser and Joliffe criteria, which only retain components with eigenvalues greater than 1 or 0.7, respectively. It also includes Cattell's Scree Plot. In order to simplify the discussion, we present the estimated PCA for each test in the "Section 5". The correlation matrix that underpins each of these estimated PCAs is placed in the "Appendix." Information on the level of model significance and the estimated KMO statistic of sampling adequacy are also provided, along with each respective correlation matrix, in the "Appendix."

With regards to the estimated PCA, only those original variables with contributions (or weights) that are greater than $( \pm$ ) 0.4 are considered to make a meaningful contribution to the construction of a component. We will indicate these with an asterisk (*) in the tables presented in "Section 5". The principal components are interpreted on the information that these variables carry (Stevens 1992). 
Note that, in order to deal with overlapping clusters of technical and service characteristics, we need to estimate separate PCAs for each of the key service characteristics that we are interested in. Turning to the dataset, this was constructed using information published in a well known, reputable, and publicly available source: the UK consumer magazine 'What Mobile Phone'. The use of a source such as this provides a dataset that is consistent and complete. The information has been cross-checked using the GSM Arena website. This website specialises in second hand mobile phones, and produces detailed product specifications for a very large list of models. Use of these independent, publicly available sources ensures other researchers can readily access and analyse the same information, allowing replicability of the results.

Information has been gathered on the characteristics for 319 mobile phones, produced and marketed during the period September 2003 to January 2008. The dataset includes handsets produced by 36 different manufactures. These include well known manufacturers such Nokia, Motorola and Sony-Ericsson, and less well known producers such as Fly, Lobster, and Primus. Data is available prior to September 2003, but information on internal and external memory only started to be published for all models from this date, as memory cards stated to be included as a standard feature. Hence, the information required to test hypotheses 1 to 3 is complete for the period September 2003 to January 2008.

Data was collected for eight variables: total volume of the handset (millimeters), weight of the phone handset (grams), total memory of the phone including card memory (megabytes), maximum lifetime of battery (hours), screen size (pixels), camera picture resolution (pixels), video picture resolution (pixels), and music playing facility (binary dummy variable).

\section{Results}

\subsection{Camera quality and ergonomics}

As discussed in "Section 3", PCA enables us to jointly test our hypotheses regarding camera quality and ergonomics. In order to test Hypothesis 1 we include the variables total memory, battery life, LCD screen pixels, and camera pixels (see "Section 3.2"). To test Hypothesis 4, the existence of a correlation between ergonomic characteristics, we additionally include the variables Physical Dimensions (volume) and Weight (see "Section 3.3").

The diagnostic statistics show that all components have eigenvalues greater than 1 , and cumulatively interpret just over $56 \%$ of the original variance across all characteristics. The estimated correlation matrix, on which the PCA is constructed, is presented in "Appendix" Table 4. It indicates that the level of model significance is within the $1 \%$ level, with an estimated KMO statistic of sampling adequacy of 0.576 . This is reasonable. 
Table 1 Estimated principal components for camera quality and ergonomics

Extraction method: principal component analysis. Rotation method: varimax with Kaiser normalization. Rotation converged in three iterations

\begin{tabular}{lcc}
\hline Variables & \multicolumn{2}{c}{ Retained components } \\
\cline { 2 - 3 } & 1 & 2 \\
\hline Physical dimensions (volume) & $0.764^{*}$ & -0.091 \\
Weight & $0.849^{*}$ & 0.187 \\
Total memory & 0.067 & $0.473^{*}$ \\
Battery life & $-0.423^{*}$ & $0.560^{*}$ \\
LCD screen pixels & $0.580^{*}$ & $0.628^{*}$ \\
Camera pixels & 0.045 & $0.767^{*}$ \\
Number of observations & 319 & 319 \\
Eigenvalues & & \\
Total & 2.007 & 1.383 \\
Percent of variance & 33.452 & 23.046 \\
Cumulative percent of variance & 33.452 & 56.498 \\
\hline
\end{tabular}

Examining Table 1, we find there are two estimated principal components for this set of variables. The second of the estimated principal components indicates a positive correlation exists between camera pixels, LCD screen pixels, total memory, and battery life. The estimated principal component thus supports Hypothesis 1.

The first estimated principal component indicates an interaction between the physical features of a mobile phone handset: its physical dimensions (volume), weight, and screen size (measured in pixels), and, thus, battery life. These support Hypothesis 4 and have the expected signs. That is to say, the physical proportions of screen size, volume, weight, are positively correlated, while battery life is negatively related to these three variables. What is interesting is that this is the first estimated principal component, i.e. the physical /ergonomic properties of the mobile phone explain the largest percentage of variance across all characteristics. This, as we shall see, is a finding common to all the tests. In this particular case, the non-technological characteristics account for almost $34 \%$ of variance, while the service and technical characteristics account for $23 \%$ of variance.

\subsection{Video quality and ergonomics}

To test Hypothesis 2 regarding the determinants of video quality we consider the variables total memory, battery life, LCD screen pixels, and video image size. Once again, in order to jointly test Hypothesis 4 regarding the ergonomic characteristics, we also include the variables physical dimensions (volume) and weight.

The diagnostic statistics for the PCA comprising these characteristic variables indicates that all components have eigenvalues greater than 1 , and cumulatively interpret around $72 \%$ of the original variance across all characteristics. "Appendix" Table 5 presents the estimated correlation matrix on which this PCA is constructed. This indicates that the level of model significance is within 
Table 2 Estimated principal components for video quality and ergonomics

Extraction method: principal component analysis. Rotation method: varimax with Kaiser normalization. Rotation converged in five iterations

\begin{tabular}{lccc}
\hline Variables & \multicolumn{3}{c}{ Retained components } \\
\cline { 2 - 4 } & \multicolumn{3}{c}{2} \\
\hline Physical dimensions (volume) & $0.783^{*}$ & 0.012 & -0.233 \\
Weight & $0.836^{*}$ & -0.102 & 0.180 \\
Total memory & 0.005 & 0.008 & $0.927^{*}$ \\
Battery life & -0.294 & $0.756^{*}$ & 0.058 \\
LCD screen pixels & $0.643^{*}$ & 0.310 & $0.442^{*}$ \\
Video image size & 0.323 & $0.761^{*}$ & -0.05 \\
Number of observations & 319 & 319 & 319 \\
Eigenvalues & & & \\
Total & 2.030 & 1.278 & 1.012 \\
Percent of variance & 33.841 & 21.294 & 16.869 \\
Cumulative percent of variance & 33.841 & 55.136 & 72.004 \\
\hline
\end{tabular}

the $1 \%$ level, with an estimated KMO statistic of sampling adequacy of 0.532 . Since this is greater than 0.5 , it is acceptable.

The estimated PCA, shown in Table 2, contains three estimated principal components for this particular set of variables. The second estimated component indicates a positive correlation between video image size (pixels) and battery life. The third estimated component indicates a positive correlation between LCD screen pixels and total memory.

Together, these offer partial support of Hypothesis 2. Clearly, the pair-wise correlation between image size and battery life is particularly strong in the case of video recording and playback. Certainly, video is far more demanding on battery life than still pictures. The recording and playback of even a short, $2-$ 3 min video clip, requires a large and constant draw of power. The strong, pairwise correlation between LCD screen pixels and memory can be explained by the fact that a mobile phone (like a PC) requires RAM memory in order to temporarily display a picture on a screen. The amount of RAM required for a short, 2-3 min video recording is therefore large, certainly in comparison to a single frame photograph.

Once again, the first estimated principal component supports Hypothesis 4 concerning an interaction between the physical/ergonomic features of a mobile phone handset: its physical dimensions (volume), weight, and screen size (measured in pixels), and battery life. Each estimated variable has the expected sign. That is to say, the physical proportions of screen size, volume, and weight are positively correlated, while battery life is negatively related to these three variables.

\subsection{Music quality and ergonomics}

Our final test examines the determinants of music quality. To test Hypothesis 3 we include the variables total memory, battery life, LCD screen pixels, and music play and storage. Once again, to jointly test Hypothesis 4 regarding ergonomic characteristics we include physical dimensions (volume) and weight. 
Table 3 Estimated principal components for music quality and ergonomics

Extraction method: principal component analysis. Rotation method: varimax with Kaiser normalization. Rotation converged in three iterations

\begin{tabular}{lcc}
\hline Variables & \multicolumn{2}{c}{ Retained components } \\
\cline { 2 - 3 } & 1 & 2 \\
\hline Physical dimensions (volume) & $0.786^{*}$ & -0.003 \\
Weight & $0.785^{*}$ & 0.371 \\
Total memory & -0.117 & $0.611^{*}$ \\
Battery life & $-0.505 *$ & $0.421^{*}$ \\
LCD screen pixels & $0.452^{*}$ & $0.701^{*}$ \\
Music play and storage & 0.102 & $0.569^{*}$ \\
Number of observations & 319 & 319 \\
Eigenvalues & & \\
Total & 2.005 & 1.217 \\
Percent of variance & 33.420 & 20.284 \\
Cumulative percent of variance & 33.420 & 53.704 \\
\hline
\end{tabular}

The diagnostic statistics for the PCA comprising these characteristic variables indicates that all components have eigenvalues greater than 1 . In this case, the selected variables cumulatively interpret almost $54 \%$ of the original variance across all characteristics. "Appendix" Table 6 presents the estimated correlation matrix on which this particular PCA is constructed. The level of model significance is, once again, within the $1 \%$ level. The estimated KMO statistic of sampling adequacy for the correlation matrix is 0.603 , which is good.

The estimated PCA, shown in Table 3, contains two estimated principal components. Again, the first estimated principal component contains the physical/ergonomic features of a mobile phone handset: its volume, weight, screen size, and battery life. This first principal component explains around $33 \%$ of total variance across all variables. Each variable has the expected sign, supporting Hypothesis 4.

The second estimated principal component indicates a positive correlation exists between music play and storage, total memory, battery life, and LCD screen pixels. This principal component explains around $20 \%$ of total variance across all variables. Each variable has the expected sign, supporting Hypothesis 3.

\section{Conclusions}

The goal of the paper was to empirically test the relationship between technical and service characteristics, as expounded by the Saviotti and Metcalfe model. The model posits that complex relationships exist between the service characteristics which consumers value, and a core set of underpinning technologies with particular technical characteristics. Rather than there being a simple oneto-one mapping between individual technical characteristics and individual service characteristics, overlapping clusters of technical characteristics can 
exist which produce a larger number of service characteristics. This relationship between technical and service characteristics has not been explored in past empirical research.

In order to address this gap in the empirical literature, the paper applied principal components analysis (PCA) to a dataset of technical and service characteristics collected on mobile phone handsets. Using PCA as an exploratory research method, the findings clearly indicate that a limited set of underpinning technologies support a set of key service characteristics that are demanded by consumers.

In addition to testing correlations between technical and service characteristics, the paper explored the existence of a cluster of ergonomic characteristics. Ergonomic design and its influence on consumer preferences was a key part of Lancaster's original theory of consumer demand. Yet this has been ignored in prior empirical research, which has preferred to concentrate on technical characteristics. Not only was this non-technological cluster consistently identified in the tests, but it was consistently the first estimated principal component, accounting for around one-third of the explained variance in each of the estimated models. Meanwhile, correlated technical and service characteristics accounted for $20 \%$ to $23 \%$ of the explained variance in our estimated models.

These research findings have a number of implications for future research. Further empirical research is required to improve our understanding of clusters of technical and service characteristics, and how these clusters develop over time. This would directly feed into current debates surrounding, for example, the work of Henderson and Clark (1990) on product architectures and the dynamics of architectural and modular innovation; and debates concerning the work of Baldwin and Clark (1997), Brusoni et al. (2001), and Langlois (2003) on the implications of modularity for organisational structures and supply chain relationships.

Another area requiring attention is the role of demand in determining the direction in which clusters of service characteristics develop over time. As one of the authors has argued elsewhere, heterogeneous consumer preferences is an important factor affecting the development of multiple niches containing products with distinct technical and service characteristics or, alternatively, dominant designs (Windrum and Birchenhall 1998; Windrum 2005). Further, the way in which heterogeneous consumer preferences evolve over time is a key factor affecting the timing of new technological products and the probability of new technologies displacing older technology products in sequential technology competitions and substitutions (Windrum and Birchenhall 2005; Windrum et al. 2009a, b). Given the findings of the current paper, future research needs to consider the empirical relationship between distributions of consumer preferences and clusters of technical and service characteristics, and how clusters change over time. As we approach the 25th anniversary of the publication of the Saviotti and Metcalfe model, it is testament to the authors that their work continues to provoke debate and to stimulate new empirical research. 


\section{Appendix}

Table 4 Estimated correlation matrix for camera quality

\begin{tabular}{|c|c|c|c|c|c|c|c|}
\hline & & $\begin{array}{l}\text { Physical } \\
\text { dimensions } \\
\text { (volume) }\end{array}$ & Weight & $\begin{array}{l}\text { Total } \\
\text { memory }\end{array}$ & $\begin{array}{l}\text { Battery } \\
\text { life }\end{array}$ & $\begin{array}{l}\text { Screen } \\
\text { pixels }\end{array}$ & $\begin{array}{l}\text { Camera } \\
\text { pixels }\end{array}$ \\
\hline \multirow[t]{6}{*}{ Correlation } & $\begin{array}{l}\text { Physical } \\
\text { dimensions } \\
\text { (volume) }\end{array}$ & 1.000 & & & & & \\
\hline & Weight & $\begin{array}{c}0.487 \\
(0.000)\end{array}$ & 1.000 & & & & \\
\hline & $\begin{array}{l}\text { Total } \\
\text { memory }\end{array}$ & $\begin{array}{c}-0.033 \\
(0.281)\end{array}$ & $\begin{array}{c}0.103 \\
(0.033)\end{array}$ & 1.000 & & & \\
\hline & $\begin{array}{l}\text { Battery } \\
\text { life }\end{array}$ & $\begin{array}{c}-0.129 \\
(0.011)\end{array}$ & $\begin{array}{c}-0.144 \\
(0.005)\end{array}$ & $\begin{array}{c}0.050 \\
(0.189)\end{array}$ & 1.000 & & \\
\hline & $\begin{array}{l}\text { Screen } \\
\text { pixels }\end{array}$ & $\begin{array}{c}0.240 \\
(0.000)\end{array}$ & $\begin{array}{c}0.532 \\
(0.000)\end{array}$ & $\begin{array}{c}0.247 \\
(0.000)\end{array}$ & $\begin{array}{c}0.030 \\
(0.299)\end{array}$ & 1.000 & \\
\hline & $\begin{array}{c}\text { Camera } \\
\text { pixels }\end{array}$ & $\begin{array}{c}0.015 \\
(0.397)\end{array}$ & $\begin{array}{c}0.114 \\
(0.021)\end{array}$ & $\begin{array}{c}0.105 \\
(0.030)\end{array}$ & $\begin{array}{c}0.221 \\
(0.000)\end{array}$ & $\begin{array}{c}0.400 \\
(0.299)\end{array}$ & 1.000 \\
\hline
\end{tabular}

Figures in brackets indicate sig. (one-tailed); determinant 0.384; Kaiser-Meyer-Olkin (KMO) measure of sampling adequacy 0.576; Bartlett's test of sphericity, approximate chi-square 305.568; df 15 , sig. 0.000

Table 5 Estimated correlation matrix for video quality

\begin{tabular}{|c|c|c|c|c|c|c|c|}
\hline & & $\begin{array}{l}\text { Physical } \\
\text { dimensions } \\
\text { (volume) }\end{array}$ & Weight & $\begin{array}{l}\text { Total } \\
\text { memory }\end{array}$ & $\begin{array}{l}\text { Battery } \\
\text { life }\end{array}$ & $\begin{array}{l}\text { Screen } \\
\text { pixels }\end{array}$ & $\begin{array}{l}\text { Video } \\
\text { image } \\
\text { size } \\
\end{array}$ \\
\hline \multirow[t]{6}{*}{ Correlation } & $\begin{array}{l}\text { Physical } \\
\text { dimensions } \\
\text { (volume) }\end{array}$ & 1.000 & & & & & \\
\hline & Weight & $\begin{array}{c}0.487 \\
(0.000)\end{array}$ & 1.000 & & & & \\
\hline & $\begin{array}{l}\text { Total } \\
\text { memory }\end{array}$ & $\begin{array}{r}-0.032 \\
(0.283)\end{array}$ & $\begin{array}{c}0.103 \\
(0.033)\end{array}$ & 1.000 & & & \\
\hline & $\begin{array}{c}\text { Battery } \\
\text { life }\end{array}$ & $\begin{array}{r}-0.130 \\
(0.010)\end{array}$ & $\begin{array}{c}-0.144 \\
(0.005)\end{array}$ & $\begin{array}{c}0.049 \\
(0.190)\end{array}$ & 1.000 & & \\
\hline & $\begin{array}{l}\text { Screen } \\
\text { pixels }\end{array}$ & $\begin{array}{c}0.239 \\
(0.000)\end{array}$ & $\begin{array}{c}0.532 \\
(0.000)\end{array}$ & $\begin{array}{c}0.247 \\
(0.000)\end{array}$ & $\begin{array}{c}0.030 \\
(0.294)\end{array}$ & 1.000 & \\
\hline & $\begin{array}{l}\text { Video } \\
\text { image size }\end{array}$ & $\begin{array}{c}0.203 \\
(0.000) \\
\end{array}$ & $\begin{array}{c}0.084 \\
(0.067) \\
\end{array}$ & $\begin{array}{c}0.069 \\
(0.110) \\
\end{array}$ & $\begin{array}{c}0.182 \\
(0.001)\end{array}$ & $\begin{array}{c}0.360 \\
(0.000) \\
\end{array}$ & 1.000 \\
\hline
\end{tabular}

Figures in brackets indicate sig. (one-tailed); determinant 0.384; Kaiser-Meyer-Olkin (KMO) measure of sampling adequacy 0.532; Bartlett's test of sphericity, approximate chi-square 301.388; df 15 , sig. 0.000 
Table 6 Estimated correlation matrix for music play and storage

\begin{tabular}{|c|c|c|c|c|c|c|c|}
\hline & & $\begin{array}{l}\text { Physical } \\
\text { dimensions } \\
\text { (volume) }\end{array}$ & Weight & $\begin{array}{l}\text { Total } \\
\text { memory }\end{array}$ & $\begin{array}{l}\text { Battery } \\
\text { life }\end{array}$ & $\begin{array}{l}\text { Screen } \\
\text { pixels }\end{array}$ & $\begin{array}{l}\text { Music play } \\
\text { and storage }\end{array}$ \\
\hline \multirow[t]{6}{*}{ Correlation } & $\begin{array}{l}\text { Physical } \\
\text { dimensions } \\
\text { (volume) }\end{array}$ & 1.000 & & & & & \\
\hline & Weight & $\begin{array}{c}0.487 \\
(0.000)\end{array}$ & 1.000 & & & & \\
\hline & $\begin{array}{l}\text { Total } \\
\text { memory }\end{array}$ & $\begin{array}{c}-0.032 \\
(0.283)\end{array}$ & $\begin{array}{c}0.103 \\
(0.033)\end{array}$ & 1.000 & & & \\
\hline & $\begin{array}{l}\text { Battery } \\
\text { life }\end{array}$ & $\begin{array}{c}-0.130 \\
(0.010)\end{array}$ & $\begin{array}{c}-0.144 \\
(0.005)\end{array}$ & $\begin{array}{c}0.049 \\
(0.190)\end{array}$ & 1.000 & & \\
\hline & $\begin{array}{l}\text { Screen } \\
\text { pixels }\end{array}$ & $\begin{array}{c}0.239 \\
(0.000)\end{array}$ & $\begin{array}{c}0.532 \\
(0.000)\end{array}$ & $\begin{array}{c}0.247 \\
(0.000)\end{array}$ & $\begin{array}{c}0.030 \\
(0.294)\end{array}$ & 1.000 & \\
\hline & $\begin{array}{l}\text { Music play } \\
\text { and storage }\end{array}$ & $\begin{array}{c}0.240 \\
(0.236)\end{array}$ & $\begin{array}{c}0.194 \\
(0.000)\end{array}$ & $\begin{array}{c}0.055 \\
(0.162)\end{array}$ & $\begin{array}{c}0.039 \\
(0.243)\end{array}$ & $\begin{array}{c}0.290 \\
(0.000)\end{array}$ & 1.000 \\
\hline
\end{tabular}

Figures in brackets indicate sig. (one-tailed); determinant 0.443 ; Kaiser-Meyer-Olkin (KMO) measure of sampling adequacy 0.603; Bartlett's test of sphericity, approximate chi-squared 256.940; $d f 15$, sig. 0.000

\section{References}

Ahamad B (1967) An analysis of crimes by the method of principal components. Appl Stat $16: 17-35$

Ahamad B (1968) A note on the interrelationships of crimes-a reply to Mrs. Walker. Appl Stat 17:49-51

Baldwin CY, Clark KB (1997) Managing in an age of modularity. Harvard Bus Rev 75(5):84-94

Brusoni S, Prencipe A, Pavitt K (2001) Knowledge specialisation, organisational coupling, and the boundaries of the firm: why do firms know more than they make? Adm Sci Q 46:597-621

Coombs R, Tomlinson M (1998) Patterns in UK company innovation styles: new evidence from the CBI innovation trends survey. Technol Anal Strateg Manag 10:295-310

Court AT (1939) Hedonic price indexes with automotive examples. The dynamics of automobile demand. General Motors Corporation, New York, pp 99-117

Dosi G (1982) Technological paradigms and technological trajectories. Res Policy 11(3):147-162

Dunteman GH (1994) Principal component analysis. In: Lewis-Beck MS (ed) Factor analysis and related techniques. Sage, London

Filiou D, Windrum P (2007) Exploration and exploitation in complementary competence domains: cooperative agreements. In: UK Biotechnology', 2007 ENEF workshop on innovation and firm dynamics. St. Catherine's College, University of Cambridge, UK, pp 17-18

Frenken K, Leydesdorff L (2000) Scaling trajectories in civil aircraft (1913-1997). Res Policy 29:331-348

Frenken K, Saviotti PP, Trommetter M (1999) Variety and niche creation in aircraft, helicopters, motorcycles and microcomputers. Res Policy 28:469-488

Gallouj F, Weinstein O (1997) Innovation in services. Res Policy 26:537-556

Gambardella A (2001) Book review of foundation of the economics of innovation: theory, measurement and practice by Hariolf Grupp. Res Policy 30:1341-1342

Griliches Z (1957) Hybrid corn: an explanation of the economics of technological change. Econometrica 25:501-522

Griliches Z (ed) (1971) Price indices and quality change. Harvard University Press, Cambridge 
Grupp H (ed) (1998) Foundation of the economics of innovation: theory, measurement and practice. Edward Elgar, Cheltenham

Henderson R, Clark K (1990) Architectural innovation: the reconfiguration of existing product technologies and the failure of established firms. Adm Sci Q 35:9-30

Kuhn TS (1962) The structure of scientific revolutions. Chicago University Press, Chicago

Lancaster KJ (1966) A new approach to consumer theory. J Polit Econ 14:133-146

Lancaster KJ (1971) Consumer demand: a new approach. Columbia University Press, New York

Langlois RN (2003) The vanishing hand: the changing dynamics of industrial capitalism. Ind Corp Change 12(2):351-385

Linden D, Reddy TB (2001) Handbook of batteries, 3rd edn. McGraw-Hill, New York

Polymers and Liquid Crystals (2008) Textbook, Case Western Reserve University and Center for Advanced Liquid Crystalline Optical Materials at Kent State University. http://plc.cwru. edu/tutorial/enhanced/files/textbook.htm. Accessed 12 December 2007

Saviotti PP (1985) An approach to the measurement of technology based on the hedonic price method and related methods. Technol Forecast Change 29:309-334

Saviotti PP (1996) Technological evolution, variety and the economy. Edward Elgar, Cheltenham

Saviotti PP, Metcalfe JS (1984) A theoretical approach to the construction of technological output indicators. Res Policy 13:141-151

Saviotti PP, Tricket A (1993) The evolution of helicopter technology: 1940-1986. Econ Innov New Technol 2:111-130

Stevens J (1992) Applied multivariate statistics for the social sciences. Lawrence Erlbaum, New Jersey

Stone R (1956) Quantity and price indexes in national accounts. OECD, Paris

Tether BS, Tajar A (2008) The organisational-cooperation mode of innovation and its prominence amongst European service firms. Res Policy 37:720-739

Trajtenberg M (1989) The welfare analysis of product innovations with an application to CAT scanners. J Polit Econ 97(2):444-479

van Schalwijk WA, Scrosati B (eds) (2002) Advances in lithium-ion batteries. Kluwer Academic/Plenum, London

Windrum P (2005) Heterogeneous preferences and new innovation cycles in mature industries: the amateur camera industry 1955-1974. Ind Corp Change 14(6):1043-1074

Windrum P, Birchenhall C (1998) Is life cycle theory a special case?: dominant designs and the emergence of market niches through co-evolutionary learning. Struct Change Eco Dyn 9:109134

Windrum P, Birchenhall C (2005) Structural change in the presence of network externalities: a co-evolutionary model of technological successions. J Evol Econ 15(2):123-148

Windrum P, García-Goñi M (2008) A neo-Schumpeterian model of health services innovation. Res Policy 37(4):649-672

Windrum P, Ciarli T, Birchenhall CR (2009a) Consumer heterogeneity and the development of environmentally friendly technologies. Technol Forecast Soc Change 76:533-551

Windrum P, Ciarli T, Birchenhall CR (2009b) Environmental impact, quality, and price: consumer trade-offs and the development of environmentally friendly technologies. Technol Forecast Soc Change 76:552-566 